\title{
Non-random mating in Adalia bipunctata (the two-spot ladybird). III. New evidence of genetic preference
}

\author{
P. O'DONALD \& M. E. N. MAJERUS \\ Department of Genetics, University of Cambridge, Downing Street, Cambridge CB2 3EH, UK
}

\begin{abstract}
Isofemale lines of ladybirds produced from a selected stock varied widely in female preference for melanic males. An attempt to repeat these results failed. The ladybirds used in the repeat experiment were collected from a wild population in which melanic frequencies had dropped from 35 to 10 per cent in 3 years. In this repeat experiment, the overall mating rate was twice that of the original experiment. The failure of the repeat experiment can be attributed either to a loss of preference or to the preference not being expressed at high mating rates. New lines were set up from a sample collected in Glasgow where high levels of preferential mating occur in the wild population. Mating tests on these lines strongly corroborated the results of the original isofemale line experiment: some lines showed high preference, others intermediate or no preference. The overall mating rate was low - one-quarter of that in the unsuccessful repeat experiment. Samples collected from areas high in melanics showed high preference. Lower levels of preference were found where melanics are less common. Where no melanics occur, preference is absent. These results provide further evidence of genetic preference in ladybirds.
\end{abstract}

Keywords: Adalia bibunctata, genetic preference, non-random mating, sexual selection, two-spot ladybird.

\section{Introduction}

In certain populations of the two-spot ladybird (Adalia bipunctata), females have a strong genetic preference to mate with the melanic phenotypes of males. Clearcut evidence of this was obtained in a number of studies carried out at the Genetics Field Station in Cambridge, using ladybirds collected at Keele in Staffordshire. By selecting females that had mated with melanic males, 'high preference' lines were produced with greatly increased frequencies of matings with melanic males. Two selection experiments carried out in 1981-1982 and 1984-1985 gave similar results: the females' propensity to choose melanic males was highly heritable and increased rapidly over a few generations (Majerus et al., 1982b; O’Donald \& Majerus, 1985).

Ladybirds from the second of these experiments were used to set up 'isofemale lines' derived from the progeny of single mating pairs. Some lines showed a very high preference indeed; other lines showed intermediate or low levels of preference, or mated randomly. A mating preference determined by a single dominant gene fitted these results closely (Majerus et al., $\{\mathrm{MOKI}\}, 1986)$. All results were strikingly consistent.

Majerus later found strong preference for melanics in a natural population in Glasgow. His data are given in Section 3 of this paper. Other populations show lower levels of preference (e.g. at Keele) or no preference at all. Generally, where melanics are most abundant (e.g. in Glasgow), we should expect to find the strongest preference: a preference gene should be more common where preferred phenotypes are common and rare, or non-existent where preferred phenotypes are rare (O'Donald, 1980). Populations should thus vary widely in levels of preferential mating.

In a recent issue of Heredity, Kearns et al., $\{$ KTVO (1992) reported the results of a new experiment on isofemale lines, also carried out in the Genetics Field Station, which appear to throw doubt on some of the evidence for genetic preference previously obtained. This experiment was an attempt to replicate MOKI's experiment on isofemale lines. Its prime purpose was to generate new high preference lines for further genetic and behavioural studies on the mating preference. KTVO found no overall preference for melanics, 
although individual lines did differ very significantly in the frequencies of matings of melanic and non-melanic males. As in some previous studies of the two-spot ladybird, female-biased sex-ratios were observed in some of the lines. The possibility was raised that ladybirds used in the mating tests of previous experiments might have been mis-sexed. We reject this possibility. In trials of the criteria Majerus developed for sexing, Randall et al., (1992) sexed ladybirds to an accuracy of 95-98 per cent. In the ladybirds used for mating tests, it was easy to pick out the odd mis-sexed individual from the containers into which the sexes had been separated. Even if some females had been mis-sexed, KTVO did acknowledge that mis-sexing would have produced no consistent bias in the detection and estimation of preference.

KTVO first attempted to estimate mating preference in lines derived from MOKI's original high preference lines. This attempt was a failure: no residual preference was found. Unfortunately, we now recognize that the methods we used to maintain the original lines may well have led to the loss of preference. Only a few individuals were kept: after eggs had been laid, the adults were discarded and a new generation reared from the eggs. Females lay eggs in successive batches. It is quite likely that our stocks were maintained by the progeny of just the few females who were the first to mate. These would have been precisely those females that had no preference. As KTVO acknowledge, our methods of maintaining stocks may well have selected strongly against females exercising a choice. Preference could also have been lost by chance in the very small numbers, perhaps only one or two females, contributing to the progeny of the next generation.

The methods KTVO used to rear, sex and maintain their ladybirds differed in some important respects from MOKI's original methods. In particular, to avoid mis-sexing, KTVO sexed ladybirds by watching them mate. With the benefit of hindsight, we consider that KTVO's methods of sexing and maintaining ladybirds must greatly have reduced the expression of any mating preference. In this paper, we first discuss KTVO's experiment in relation to the previous experiment. We then give more recent evidence of preferential mating in the two-spot ladybird. Some of this evidence consists of observations of mating frequencies in natural populations collected by observers taking part in the Cambridge Ladybird Survey. We also report the results of hitherto unpublished mating tests.

\section{Repeat of an isofemale line experiment}

Kearns et al. $\{$ KTVO\} (1992) attempted to repeat the results of an earlier experiment on isofemale lines (Majerus et al. \{MOKI\}, 1986). MOKI had produced some lines with very high levels of expression of preference - about 90 per cent of females mating preferentially with melanic males. The levels of preference among the different lines were consistent with a single gene model: one parent from each of the high preference lines was presumed to be homozygous for the preference gene. KTVO's repeat experiment was carried out with the aim of producing new lines for further genetic and behaviour analyses of the mechanism of preferential mating. The two experiments differed at the outset in one important respect. In both experiments, the ladybirds had been collected on the campus at Keele University. But in MOKI's experiment, they were strongly selected to raise the level of preference before the lines were started. After nine generations of selection in the selected line, single pairs were taken to produce the isofemale lines. KTVO's lines were established from the original sample of ladybirds collected at Keele. And here there is another important difference. In Majerus' original samples, hundreds of ladybirds were collected and thousands were classified in the field, the melanics occurring at a frequency of 35 per cent at Keele (see, for example, O'Donald, et al., 1984). KTVO managed to collect a total of only 61 ladybirds of which six were melanic: the melanic frequency appeared to have dropped from 35 to 10 per cent in the period between the collection of the two samples. A considerable drop in preference was thus to be expected. KTVO's sample was collected in late August, 1987 (rather late in the season to find many ladybirds) and ladybirds were generally scarce in 1986 and 1987. A bottleneck in population size may have contributed to the rapid decline in melanic frequency.

\section{What is the chance of collecting a ladybird with the preference gene?}

KTVO state that, in the sample of 61 ladybirds, a ladybird with a preference would be collected with a probability greater than 95 per cent, given that the preference gene occurred at a frequency of 2 per cent. This is not quite correct. The preference gene must have a frequency of 2.43 per cent to give a probability of collection of 95 per cent. The single preference gene model implied a gene frequency of 12 per cent when the original samples were collected in 1981 and 1984 (Majerus et al., 1986). So, unless the frequency of the preference gene had fallen even more drastically than the frequency of the gene for the preferred phenotype, we should have expected to collect at least one or two ladybirds carrying the preference gene. This is not the same, however, as detecting the preference within the 13 isofemale lines that were established from the 61 ladybirds. If the preference gene frequency had 
declined to half of its value in 1981 , the probability of finding a preference in only one line or none would be about 18 per cent. One of the 13 lines did show a preference for melanics at a level to be expected if one of the parents were heterozygous for the preference. KTVO's results are not inconsistent with a decline in preference gene frequency such as may well have taken place in the Keele population.

\section{Was preference expressed in KTVO's isofemale lines?}

In KTVO's isofemale lines, the mating frequencies changed during the course of the mating tests on the lines. In the first line tested (line 11E), a significant preference for melanics was shown. In subsequent lines, no preference was observed. In lines tested towards the end of the experiment, matings increasingly favoured the non-melanics. Figure 1 in KTVO's paper shows the frequency of matings of melanic males in each isofemale line in relation to the mean date of testing. Starting with an excess of melanics, the melanic matings decline, giving an excess of non-melanic matings in later lines. This regression on the date of testing is highly significant. As KTVO had fewer melanic males than non-melanics for testing female preference, the same melanic males were used again and again in the tests. The decline in melanic matings may plausibly be explained, as KTVO acknowledge, by the melanic males slowly becoming 'worn out' as later lines were tested. The females may thus have had no opportunity to express any preference for melanic males. MOKI allowed each male a 48-h 'recovery period' before including them again in a mating test.

Majerus sexed all the ladybirds himself by eye. Lacking this ability, KTVO sexed theirs by observing pairing and mounting - a laborious process: it took many days to sex enough ladybirds for the mating tests on a line. Majerus produced many times more ladybirds for testing than KTVO. MOKI's experiments are therefore on a far larger scale. This difference in procedure may have produced another striking difference in the experimental results of the two experiments. The rate at which pairs were formed in the mating tests was twice as high in KTVO's experiment as compared to the rate in MOKI's experiment. In KTVO's mating tests, 54 per cent of the ladybirds had mated at the end of each of the half-hour periods into which the tests were divided: 26 per cent had mated in MOKI's tests. These figures are average percentages for all lines of each of the two experiments. They are obtained from the total number of ladybirds that mated in all tests divided by the total number used in testing. The longer the time taken to sex the ladybirds in KTVO's experiments, the longer the females were kept before testing: they may just have been more eager to mate in KTVO's experiments. The very high mating rates seen in KTVO's experiment would presumably reduce the expression of preference: a female who will mate almost immediately on being presented with a male is unlikely to exercise much of a choice. Even speciesspecific barriers to mating have been shown to disappear if females are particularly eager to mate. Ireland et al. (1986) found that Adalia bipunctata and $A$. decempunctata hybridized readily if the sexes were kept as virgins for 2 weeks before being placed together.

We conclude, with the benefit of hindsight of course, that KTVO's experimental procedure produced conditions in which any mating preference, even if it existed, would have been unlikely to have been expressed. The twofold difference in mating rate is sufficient to show that conditions were very different in the two experiments.

\section{Further data on preferential mating in ladybirds}

In this section we present new data, hitherto unpublished, on preferential mating in ladybirds collected from several different sources. As well as observations of mating frequencies in natural populations and samples taken from them, Majerus also set up some isofemale lines derived from a sample collected in Glasgow where melanics occur at high frequencies. One of Majerus' contributors to the Cambridge Ladybird Survey, Mr I. T. Harding, recorded a sample of both mating and non-mating ladybirds from the wild Glasgow population. Like Majerus' earlier Glasgow sample, the wild Glasgow population shows high preferential mating of melanics. Table 1 shows the data supplied by Mr Harding: 57 per cent of melanic males mate preferentially in Glasgow - a similar level of preference to that attained in the selected Keele line from which MOKI's isofemale lines were originally derived.

Table 2 gives the results of Majerus' mating tests on the isofemale lines derived from his Glasgow sample. Some lines show very high preference, others intermediate preference or low or no preference. The sample from Glasgow thus produced a distribution of preference among lines similar to that of MOKI's original lines. In KTVO's isofemale lines, the mating rate was twice that in MOKI's original lines. In Majerus' new lines, derived from the unselected Glasgow sample, the mating rate was half that in MOKI's lines and hence, of course, one-quarter of that in KTVO's lines. (Table 2 shows that in the tests on the 
Table 1. Preferential mating in a natural population in Glasgow

(i) Numbers of individuals (not mating)

\begin{tabular}{lr}
\hline Phenotype & Number in sample \\
\hline quadrimaculata $(\mathrm{Q})$ & 184 \\
sexpustulata $(\mathrm{S})$ & 55 \\
typica $(\mathrm{T})$ & 84 \\
annulata $(\mathrm{A})$ & 14 \\
duodecempustulata $(\mathrm{D})$ & 2 \\
Other melanics & 3
\end{tabular}

(ii) Numbers of mating pairs

\begin{tabular}{|c|c|c|c|c|c|}
\hline \multirow[b]{2}{*}{ Female phenotypes } & \multicolumn{5}{|c|}{ Male phenotypes } \\
\hline & $\mathrm{Q}$ & $S$ & $\mathrm{~T}$ & A & Totals \\
\hline Q & 29 & 10 & 4 & 0 & 43 \\
\hline S & 14 & 6 & 2 & 1 & 23 \\
\hline $\mathrm{T}$ & 7 & 5 & 1 & 1 & 14 \\
\hline A & 1 & 0 & 0 & 0 & 1 \\
\hline Totals & 51 & 21 & 7 & 2 & 81 \\
\hline
\end{tabular}

(iii) Estimates of preference for melanics

\begin{tabular}{llrlll}
\hline & \multicolumn{3}{l}{ Mating } & \multicolumn{3}{l}{ Not-mating } & Preference ( \pm S.E.) \\
& $M$ & $N m$ & $M$ & $N m$ & \\
Males & 72 & 9 & 121 & 50 & $0.569 \pm 0.112$ \\
Females & 66 & 15 & 121 & 50 & $0.319 \pm 0.131$ \\
\hline
\end{tabular}

The melanic class $(\mathbf{M})$ includes quadrimaculata and sexpustulata $(\mathrm{M}=\mathrm{Q}+\mathrm{S})$. Nonmating individuals have been assumed to consist of equal numbers of males and females.

Glasgow lines, a total of 1,046 ladybirds mated out of a total of 7,710 used: an average 13.6 per cent mated, compared to 26 per cent in MOKI's experiment and 54 per cent in KTVO's experiment.) Individuals who are less eager to mate are likely to be more choosy, so we should expect preference to be expressed more strongly at lower mating rates. KTVO's attempt to generate new isofemale lines from the wild population at Keele may record either a rapid collapse of both melanism and preference in the Keele population or reduced expression of preference among frustrated ladybirds.

Tests for non-random mating have been carried out on ladybird samples taken from different populations in England and Scotland. Keele was the first British population in which sexual selection for melanics was demonstrated (Majerus et al., 1982a). Samples from the Keele population were then used for our first experiments to select for preference (Majerus et al., $1982 \mathrm{~b}$ ) and to set up MOKI's original isofemale lines. Table 3 shows the results of more recent tests of nonrandom mating from different populations. Females from the Cambridge populations show no significant preference for melanics: where there are no melanics, there is no preference. Preferential matings are observed in females from the Midlands (Birmingham and Keele). In Glasgow where melanics are common, highly significant preference is found. These results show variation in preference between populations which is entirely consistent with the preference having a genetic basis.

\section{Conclusion}

In this paper, we confront the problem posed by Kearns et al's (KTVO's) isofemale line experiment, the 
Table 2. Formal mating tests on female progeny of single-pairs from a Glasgow sample

\begin{tabular}{|c|c|c|c|c|c|}
\hline \multirow[b]{2}{*}{ Brood } & \multicolumn{2}{|c|}{ Phenotypes } & \multirow{2}{*}{$\begin{array}{l}\text { Total } \\
\text { tested }\end{array}$} & \multirow{2}{*}{$\begin{array}{l}\text { Matings } \\
\text { (male ratio) }\end{array}$} & \multirow{2}{*}{$\begin{array}{l}\text { Preference } \\
( \pm \text { S.E. })\end{array}$} \\
\hline & 우우 & రేర & & & \\
\hline $\mathrm{G}_{1}$ & Q & $\mathrm{Q}, \mathrm{T}$ & 730 & Q33:T36 & $-0.045 \pm 0.115$ \\
\hline & $\{\mathrm{Q}$ & $\mathrm{Q}, \mathrm{T}$ & 590 & Q43:T20 & $0.378 \pm 0.109$ \\
\hline $\mathrm{G}_{2}$ & $\left\{\begin{array}{l}\mathrm{T} \\
\mathrm{T}\end{array}\right.$ & Q.T & 530 & Q38:T21 & $0.300 \pm 0.116$ \\
\hline $\mathrm{G}_{3}$ & Q & $\mathrm{Q}, \mathrm{T}$ & 470 & Q37:T28 & $0.147 \pm 0.113$ \\
\hline & $\int S$ & $\mathrm{~S}, \mathrm{~T}$ & 520 & S46 :T13 & $0.574 \pm 0.098$ \\
\hline $\mathrm{G}_{5}$ & $\{\mathrm{~T}$ & $\mathrm{S}, \mathrm{T}$ & 400 & S49:T 10 & $0.678 \pm 0.086$ \\
\hline \multirow[t]{2}{*}{$\mathrm{G}_{6}$} & S & $\mathrm{S}, \mathrm{T}$ & 610 & $\mathrm{~S} 59: \mathrm{T} 2$ & $0.937 \pm 0.041$ \\
\hline & Q & $\mathrm{S}, \mathrm{T}$ & 470 & S27 :T34 & $-0.124 \pm 0.120$ \\
\hline \multirow[t]{2}{*}{$\mathrm{G}_{7}$} & $\{s$ & $\mathrm{Q}, \mathrm{T}$ & 300 & Q31:T31 & $0.000 \pm 0.113$ \\
\hline & $\mathrm{T}$ & $\mathrm{S}, \mathrm{T}$ & 400 & S38 :T 31 & $0.110 \pm 0.108$ \\
\hline $\mathrm{G}_{8}$ & Q & $\mathrm{Q}, \mathrm{T}$ & 370 & Q38:T20 & $0.328 \pm 0.112$ \\
\hline $\mathrm{G}_{9}$ & $Q$ & Q, T & 400 & Q43:T 19 & $0.406 \pm 0.104$ \\
\hline & $\int S$ & $\mathrm{~S}, \mathrm{~T}$ & 430 & S33 :T34 & $-0.016 \pm 0.112$ \\
\hline $\mathrm{G}_{11}$ & $\{\mathrm{~T}$ & $\mathrm{S}, \mathrm{T}$ & 410 & S31:T26 & $0.094 \pm 0.122$ \\
\hline & $\int S$ & $\mathrm{~S}, \mathrm{~T}$ & 360 & S54 :T5 & $0.842 \pm 0.062$ \\
\hline $\mathrm{G}_{13}$ & $\left\{\begin{array}{l}\mathrm{T} \\
\mathrm{T}\end{array}\right.$ & $\mathrm{S}, \mathrm{T}$ & 300 & $\mathrm{~S} 59: \mathrm{T} 1$ & $0.970 \pm 0.027$ \\
\hline $\mathrm{G}_{16}$ & $\mathrm{Q}$ & $\mathrm{Q}, \mathrm{T}$ & 420 & Q30:T26 & $0.076 \pm 0.123$ \\
\hline
\end{tabular}

The column of totals tested gives the total number of males used in the run of tests: males were used more than once in successive runs carried out on alternate days. $Q$, $\mathrm{S}$ and $\mathrm{T}$ represents the phenotypes quadrimaculata, sexpustulata and typica. The phenotypes were tested in the ratio $1: 1$. In line G16, for example, a total of $210 \mathrm{Q}$ and $210 \mathrm{~T}$ males were tested.

Table 3. Miscellaneous mating tests carried out in population cages on ladybirds collected in different localities

\begin{tabular}{|c|c|c|c|c|c|c|}
\hline \multirow[b]{2}{*}{ Locality } & \multirow[b]{2}{*}{ Ratio in cage } & \multicolumn{4}{|c|}{ Matings observed } & \multirow{2}{*}{$\begin{array}{l}\text { Preference } \\
( \pm \text { S.E. })\end{array}$} \\
\hline & & $\mathrm{Q} \times \mathrm{Q}$ & $\mathrm{Q} \times \mathrm{T}$ & $\mathrm{T} \times \mathrm{Q}$ & $\mathrm{T} \times \mathrm{T}$ & \\
\hline Glasgow 1 & $50 \mathrm{Q}: 50 \mathrm{~T}$ & 41 & 37 & 21 & 22 & $0.289 \pm 0.087$ \\
\hline Glasgow 2 & 50Q:50T & 59 & 50 & 28 & 31 & $0.298 \pm 0.074$ \\
\hline Keele 1 & $50 \mathrm{Q}: 50 \mathrm{~T}$ & 38 & 33 & 16 & 20 & $0.327 \pm 0.091$ \\
\hline Keele 2 & $70 \mathrm{~T}: 30 \mathrm{Q}$ & 24 & 36 & 30 & 54 & $0.167 \pm 0.059$ \\
\hline Cambridge 1 & $\begin{array}{l}\text { 100T Cb. } \\
70 \mathrm{~T}: 30 \mathrm{Q} \mathrm{Ke}\end{array}$ & 12 & 31 & 33 & 61 & $0.020 \pm 0.057$ \\
\hline Cambridge 2 & $\begin{array}{l}50 \mathrm{~T} \mathrm{Cb} . \\
35 \mathrm{~T}: 15 \mathrm{Q} \mathrm{Ke} .\end{array}$ & 6 & 16 & 13 & 32 & $0.040 \pm 0.82$ \\
\hline Birmingham & $70 \mathrm{~T}: 30 \mathrm{Q}$ & 13 & 29 & 20 & 44 & $0.137 \pm 0.68$ \\
\hline
\end{tabular}

These data show hitherto unpublished results of tests carried out in 1985 on samples collected in areas (i) where no melanics occur (Cambridge), (ii) where melanics occur at frequencies of about 20-35 per cent (Keele and Birmingham), and (iii) where melanics are common (Glasgow). 'Cb.' refers to stock of Cambridge origin; 'Ke.' refers to stock of Keele origin. In the cages, mates are assumed to be chosen with replacement from the fixed ratio stated. 
results of which failed to confirm those of Majerus et al.'s (MOKI's) original experiment. This failure was a nasty shock: the results of MOKI's experiment were so clear-cut and decisive in demonstrating a genetic preference for melanics. In some lines, apparently homozygous for preference, 85 per cent of females mated preferentially with melanics. This was consistent with a model based on a single major preference gene. KTVO's results showed no overall preference for melanics, although the lines differed very significantly in the mating frequencies of melanic and non-melanic males.

KTVO's lines came from a population where the frequency of melanics had dropped from 35 to 10 per cent in 3 years. MOKI's lines were derived from a line that had previously been selected for high preference. The mating rate in KTVO's experiment was twice that in MOKI's experiment. This more rapid mating would presumably have reduced the expression of any preference that may have remained in KTVO's lines.

Majerus' new isofemale line experiment, reported here, gave results similar to those of MOKI: although this new experiment is only small-scale, some lines do show very high levels of preference, comparable to MOKI's high preference lines. Majerus' new lines were derived from a sample collected in Glasgow where high frequencies of melanics and high levels of preferential mating are seen in the natural population. Both the origin of the lines from a high preference population, the methods of maintaining the lines and the results of testing them closely reflect the origin, conditions and results of MOKI's first experiment. Majerus' new experiment thus strongly corroborates the original evidence for a genetic preference in ladybirds. We conclude that the failure of KTVO's attempt at corroboration was a consequence either of the preference having been lost, or not having been expressed.

Natural populations of ladybirds show variations in preferential mating that are entirely consistent with a genetic preference for melanics.

\section{References}

IRELAND, H., KEARNS, P. W. E. AND MAJERUS, M. E. N. 1986. Interspecific hybridisation in the Coccinellids: some observations on an old controversy. Entomol. Rec., 98, 181-185.
KEARNS, P. W. E., TOMLINSON, 1. P. M., VELTMAN, C. J. AND O'DONALD, P. 1992. Non-random mating in the two-spot ladybird (Adalia bipunctata). II. Further tests for female mating preference. Heredity, 68, 385-389.

MAJERUS, M. E. N., O'DONALD, P., KEARNS, P. W. E. AND IRELAND, H. 1986. Genetics and the evolution of female choice. Nature, 321, 164-167.

MAJERUS, M. E. N., O'DONALD, P. AND WEIR, J. 1982a. Evidence for preferential mating in Adalia bipunctata. Heredity, 49 , 37-49.

MAJERUS, M. E. N., O'DONALD, P. AND WEIR, J. 1982b. Female mating preference is genetic. Nature, 300, 521-523.

o'Donald, P. 1980. Genetic Models of Sexual Selection. Cambridge University Press, Cambridge.

O'DONALD, P., DERRICK, M., MAJERUS, M. E. N. AND WEIR, J. 1984. Population genetic theory of the assortative mating, sexual selection and natural selection of the two-spot ladybird, Adalia bipunctata. Heredity, 52, 43-61.

O'DONALD, P. AND MAJERUS, M. E. N. 1985. Sexual selection and the evolution of preferential mating in ladybirds. I. Selection for high and low lines of female preference. Heredity, 55, 401-412.

RANDALl, K., MAJERUS, M. E. N. AND FORGE, H. 1992. Characteristics for sex determination in British Ladybirds (Coleoptera: Coccinellidae). The Entomologist, 111, 109-122.

\section{Appendix}

The estimates of preference given in Table 2 assume hypergeometric sampling (i.e. without replacement) from the finite totals used. The average frequency of unmated melanics is given by

$v=(2 M-m) /(2 N-n)$.

In this expression, $N$ is the total number of ladybirds used in the test (the number given in the column headed 'Total tested'). $M$ is the total number of melanics used ( $M=N / 2$ in each of these tests). $m$ is the number of melanics that mated (the first figure in the matings column) and $n$ the total number that mated (the sum of the two figures in the matings column). The estimate of preference is then given by

$\gamma=[m(1-v)-v(n-m)] /[n(1-v)]$

with variance

$\operatorname{var}=(1-\gamma)(\gamma+v-\gamma v)(N-n) /[n(1-v)(N-1)]$. 